\title{
Analysis of elemental composition and porosity of mesoporous iridium-titanium mixed oxide thin films for energy application by SEM/EDS
}

\author{
R. Sachse ${ }^{1}$, V.-D. Hodoroaba ${ }^{2}$, A. Hertwig ${ }^{3}$, Leyla Kotil $^{1}$ and R. Kraehnert ${ }^{1}$ \\ 1. Technical University of Berlin, Berlin, Germany. \\ 2. Federal Institute for Materials Research and Testing (BAM), Division 6.1, Berlin, Germany. \\ 3. Federal Institute for Materials Research and Testing (BAM), Division 6.7, Berlin, Germany.
}

Porous materials play an important role in several fields of technology, especially for energy applications like photovoltaics, electrolysis or batteries. The activity of porous films is affected by properties like porosity, film thickness, chemical composition of the material as well as the crystallinity of the framework. The complex morphology of such porous films constitutes a challenge even for modern analytical techniques and requires new approaches employing the combination/complementation of data of different analytical methods. In this contribution we characterize thin mesoporous iridium-titanium mixed oxide film properties by Electron Probe Microanalysis (EPMA) with energy dispersive X-ray spectroscopy (EDS) at an SEM.

Mesoporous iridium oxide - titanium oxide $\left(\mathrm{IrO}_{\mathrm{x}}-\mathrm{TiO}_{\mathrm{x}}\right)$ films were prepared via dip-coating of a solution containing a triblock-copolymer as structure-directing agent, an iridium precursor as well as a titanium precursor in ethanol. $\mathrm{IrO}_{\mathrm{x}}-\mathrm{TiO}_{\mathrm{x}}$ films were synthesized with different amounts of iridium and calcined in air (Figure 1). The SEM micrographs in Figure 1 reveal for all films the achievement of a well-ordered mesopore structure and homogeneous films with thicknesses between $67 \mathrm{~nm}$ and $152 \mathrm{~nm}$.

For the determination of film elemental composition and porosity, EPMA can be used as part of a combined SEM/EDS/STRATAGem analysis [1,2]. Elemental compositions (in wt\%) and mass depositions (in $\mu \mathrm{g} \mathrm{cm}^{-2}$ ) of $\mathrm{IrO}_{\mathrm{x}}-\mathrm{TiO}_{\mathrm{x}}$ films were calculated with the thin film analysis software STRATAGem via $k$-values measured with SEM/EDS [3]. Pure bulk Ir, $\mathrm{TiO}_{2}$ and $\mathrm{Si}$ were measured as

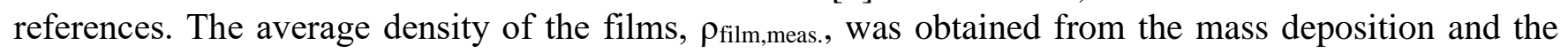
film thickness as measured by the cross-section SEM. The porosity $P$ was then extracted from the

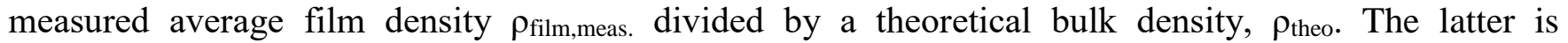
calculated from the weight fractions of $\mathrm{IrO}_{\mathrm{x}}$ and $\mathrm{TiO}_{\mathrm{x}}$ as determined with STRATAGem and the bulk mass densities of $\mathrm{IrO}_{2}$ and $\mathrm{TiO}_{2}$ (rutil) from literature (equation 1).

Figure $2 \mathrm{a}$ displays the $k$-values for Ir L $\alpha$, Ti $\mathrm{K} \alpha, \mathrm{O} \mathrm{K} \alpha$ and $\mathrm{Si} \mathrm{K} \alpha$ from EDS spectra of films as measured at accelerating voltages of $15,20,25$, and $30 \mathrm{kV}$ by using a high-throughput SDD EDS detector. The curves present the fitting results from the STRATGem software, which are in fair agreement with the measured $k$-values. Figure $2 \mathrm{~b}$ presents the correlation between the Ir mass fraction as measured with STRATAGem and the nominal Ir-loading.

The application of the SEM/EDS/STRATAGem approach for accurate porosity determination on pure mesoporous $\mathrm{TiO}_{\mathrm{x}}$ films [1] and pure porous $\mathrm{IrO}_{\mathrm{x}}$ films [4] has been recently demonstrated. The porosities of the series of pure $\mathrm{IrO}_{x}, \mathrm{TiO}_{\mathrm{x}}$ and mixed $\mathrm{IrO}_{\mathrm{x}}-\mathrm{TiO}_{\mathrm{x}}$ films as determined in this study are shown in Figure 2c. 
The contribution will assess in detail the advantages and limitations of the combined SEM/EDS/STRATAGem analysis for the morphology and porosity of thin metal oxide films. Moreover, the comparison with other measurement techniques and the combination of datasets from multiple measurements will be discussed.

References

$$
P=1-\frac{\rho_{\text {film, meas }}}{\rho_{\text {theo }}} ; \text { with } \frac{1}{\rho_{\text {theo }}}=\sum \frac{\omega_{i}}{\rho_{i}}
$$

[1] E Ortel et al., Anal. Chem. 88 (2016), p. 7083.

[2] V-D Hodoroaba et al., Surf. Interface Anal. 44 (2012), p. 1459.

[3] Stratagem version 6.7, SAMx, 4, rue Galilée, 78280 Guyancourt, France.

[4] R Sachse et al., Microscopy and Microanalysis 24 (2018), p. 762.

[5] The authors acknowledge funding from the European Metrology Programme for Innovation and Research (EMPIR) Project 16ENG03 Hybrid metrology for thin films in energy applications (HyMET).

a) HR-SEM top-view $_{\text {Ho }}$

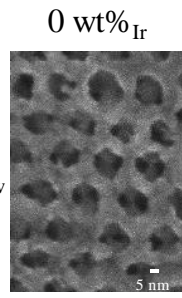

b) $\mathrm{SEM}_{\text {cross-section }}$

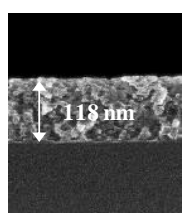

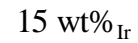
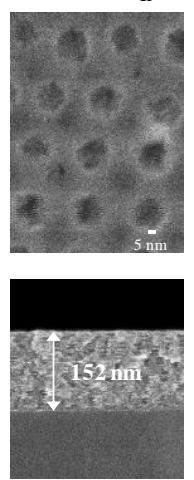
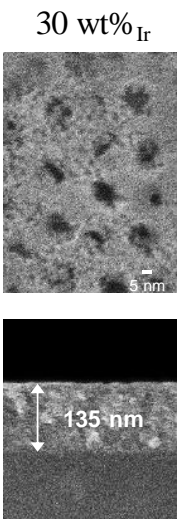
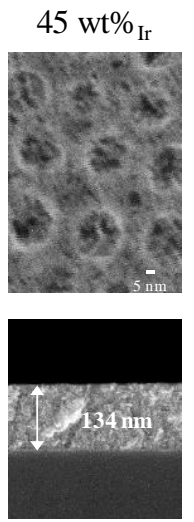

$60 \mathrm{wt} \%$ Ir
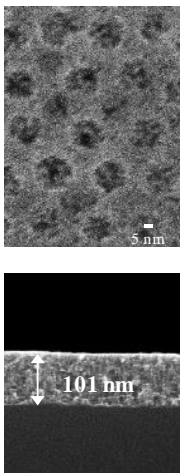
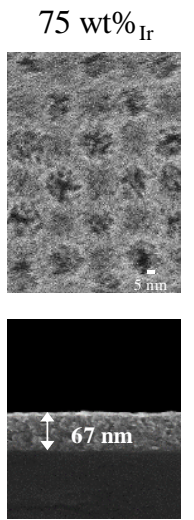

$100 \mathrm{wt} \%_{\mathrm{Ir}}$
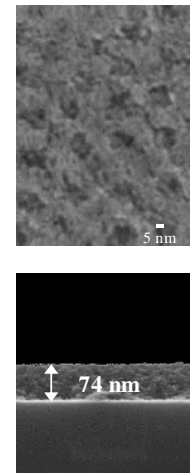

Figure 1. SEM micrographs of a mesoporous $\mathrm{IrO}_{\mathrm{x}}-\mathrm{TiO}_{\mathrm{x}}$ films with different amount of $\mathrm{Ir}$, calcined in air. a) top-view HR-SEM images and b) cross-section SEM micrographs of the films.
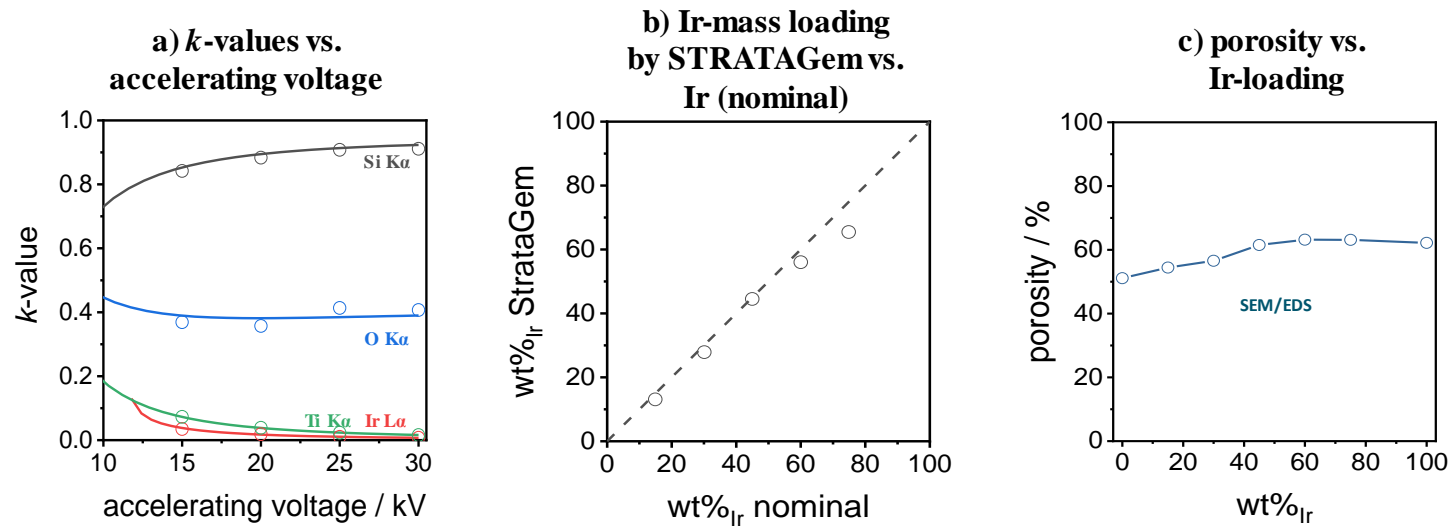

Figure 2. Results of SEM/EDS/STRATAGem analysis of mesoporous $\mathrm{IrO}_{\mathrm{x}}, \mathrm{TiO}_{\mathrm{x}}$ and $\mathrm{IrO}_{\mathrm{x}}-\mathrm{TiO}_{\mathrm{x}}$ films. a) $k$-values $v s$ accelerating voltage of the $30 \mathrm{wt} \% \mathrm{Ir} \mathrm{IrO}_{\mathrm{x}}-\mathrm{TiO}_{\mathrm{x}}$ film. Open dots represent the measured values for Ir L $\alpha$ (red), Ti K $\alpha$ (green), $\mathrm{O} \mathrm{K} \alpha$ (blue) as well as $\mathrm{Si} \mathrm{K} \alpha$ (black) and the curves indicate the STRATAGem fit. b) Ir-mass loadings from STRATAGem $v s$ the nominal Ir-loading. c) film porosities determined from the EPMA approach for the complete set of $\mathrm{IrO}_{\mathrm{x}}-\mathrm{TiO}_{\mathrm{x}}$ films. 